\title{
Application of a sense of coherence-based leadership for productivity and health at Scania
}

\section{Bengt Halling*}

Department of Industrial Design, Industrial Management and

Mechanical Engineering,

University of Gavle, Sweden,

Kungsbäcksvägen 47, 80176 Gävle, Sweden

and

Division of Ergonomics,

Royal Institute of Technology,

KTH Flemingsberg, Hälsovägen $11 \mathrm{C}$,

14157 Huddinge, Sweden

Email: bengt.halling@hig.se

*Corresponding author

\section{Peter Magnusson}

Scania CV AB,

Sandåsavägen 7 ,

57236 Oskarshamn, Sweden

Email: peter.magnusson@scania.com

\section{Martin Lyckström}

\section{Scania CV AB,}

Vagnmakarvägen 1, 15187 Södertälje, Sweden

Email: martin.lyckstrom@scania.com

\section{Katarina Wijk}

Centre for Research and Development, Region Gävleborg, Lasarettsvägen 1, 80187 Gäv, Sweden and

Faculty of Health and Occupational Studies, University of Gävle,

Kungsbäcksvägen 47, 80176 Gävle, Sweden and

Department of Public Health and Caring Sciences, Uppsala University,

BMC, Husargatan 3, 75122 Uppsala, Sweden

Email: katarina.wijk@regiongavleborg.se 
Abstract: The purpose was to explore if sense of coherence (SOC) theory can be used in human factors ergonomics (HFE) practice as a leadership approach to decrease the rate of sick leave and rehabilitation cases and increase work attendance among assembly personnel without impeding productivity. Via three studies carried out at the Swedish truck manufacturer Scania, we investigated the company's key performance indicators and documented meetings with managers during the intervention. The results show that SOC can be used in HFE practice and that productivity, quality and attendance at work increased, while rehabilitation cases decreased. Our conclusion is that a health promotion approach among managers is essential in a lean organisation that aims to reduce waste in the company and optimise human capability and thereby productivity. SOC theory can support the creation of workplaces that are high performing and healthy, starting with concerns for the people creating the output.

Keywords: leadership; lean; health promotion; productivity; manufacturing; sense of coherence; SOC; Sweden; workplace; job satisfaction; performance; meaningfulness.

Reference to this paper should be made as follows: Halling, B., Magnusson, P., Lyckström, M. and Wijk, K. (2019) 'Application of a sense of coherence-based leadership for productivity and health at Scania', Int. J. Human Factors and Ergonomics, Vol. 6, No. 2, pp.179-194.

Biographical notes: Bengt Halling is a university teacher from the University of Gävle and PhD student from the KTH in Stockholm, Sweden. He obtained his Master's of Science in Pedagogics, Master's of Public Health Science and Licentiate of Philosophy in Technology and Health. He has been teaching Health Pedagogy and Public Health Science from the University of Gävle. He currently teaches and develops the concept of human lean at the Human Lean Center, University of Gävle. His main research interests concern the areas of lean, leadership, organisational change and health promotion and particular the concept of human lean.

Peter Magnusson is Plant Manager at Scania in Oskarshamn. He has also been the Manager in different positions for almost 20 years at Scania, covering the areas of engineering, logistics and production. During this period, Scania Production System (SPS) have been developed and he has deep knowledge of both implementing and developing ways of working with SPS.

Martin Lyckström is the Head of Scania Way Office which is a corporate lean office with the overall responsibility to secure a company wide application of The Scania Way. He has been working at Scania for 15 years, covering several different management jobs within both production and logistics and HR.

Katarina Wijk is a Professor in Occupational Health Sciences from the Faculty of Health and Occupational Studies. She works as the Head of the Department of Research and Development at Region Gavleborg. She is also affiliated to the Department of Public Health and Caring Science at the Uppsala University. Her research is mainly in the area of health promotion, implementation science and public health issues. 


\section{Introduction}

Manufacturing and other industries strive for profit, and humans are an important factor for profit. To optimise profit, interventions and production systems are implemented. Previous studies have indicated that performance and job satisfaction increased when implementing lean production in combination with human resource practice (Rodríguez et al., 2015). There is a need for more knowledge about how human aspects like sick leave and productivity in manufacturing are influenced by the implementation of interventions and production systems. Three workplaces at a large manufacturing company in Sweden were studied when implementing a leadership approach based on sense of coherence (SOC) in combination with lean. To create healthy workplaces, a holistic approach may be important, one that encompasses health as well as productivity (Kelloway and Day, 2005). Edwards and Jensen (2014) argue that ergonomics aims to ensure that design or redesign of production systems considers productivity as well as employee well-being. An important factor for success is to involve different stakeholders (Dul et al., 2012; Neumann et al., 2009). It is also important to acknowledge that normal life events such as career changes, illness or retirement can influence stakeholders and thereby change the project as a whole. According to Dul et al. (2012), human factors ergonomics (HFE) aims to use system design to contribute to the creation of workplaces that are both healthy and high performing, focussing on two related outcomes: well-being and performance. They argue that companies can accomplish the two outcomes by fitting the work environment to the humans. However, the researchers also believe that HFE is underexploited and facing challenges in market readiness and applications. That means that there is a lack of knowledge on how to fit the work environment to the humans, with the goal of accomplishing the two outcomes. Dul et al. (2012) argue that managers as decision makers have an important role in HFE. That is supported by Tappura et al. (2014), who assert that quality of working life, innovativeness, and an organisation's performance can be improved if managers' competence and knowledge about occupational health is developed. Those factors are believed to affect sick leave and rehabilitation.

\subsection{The case company}

The Swedish truck manufacturer Scania has been pointed out as successful with their lean approach (Robinson and Schroeder, 2009; Miina, 2012). Scania has systematised their lean approach in the Scania Production System (SPS), which it regards as a powerful tool that has contributed to their business success (Scania, 2017). The management team at Scania's axle and gearbox assembly unit also considers SPS to be a well-functioning system with positive impact on productivity and quality. Yet managers found that the rate of sick leave and rehabilitation cases among assembly personnel was too high. The management team wanted to change the health among assembly personnel for the better and thereby decrease the rate of sick leave and rehabilitation cases and increase work attendance. They decided the changes had to start with themselves and that they were responsible for implementation of change. However, they did not know what kind of changes would promote health among the personnel.

In spring 2012, Scania contacted the first author to arrange a lecture on health promotion and discuss the possibility that health promotion theory could help the 
management team at the unit improve their leadership behaviour. The goal was to increase health without impeding productivity. The managers of the rear axle and front axle assembly lines, inspired by HFE, also started to discuss how to practise HFE at the workplaces and decided to try to base their leadership on the health promotion theory SOC. At the end of 2013, the management team at Scania's axle and gearbox assembly unit was disbanded and replaced by a new one, and the SOC-based leadership project ended. However, on January 1, 2014, the production manager from the rear axle assembly line (second author) moved to Scania's engine plant as production manager with the mission to repeat the experiment, this time at a larger unit, to find out if the SOC-based managerial approach could work in a bigger workplace. The study was done at three workplaces at Scania: the rear axle assembly line, the front axle assembly and the engine plant, all located in Södertälje, Sweden.

\subsection{Purpose}

The purpose was to explore if SOC can be used as a leadership approach in HFE practice to decrease the rate of sick leave and rehabilitation cases and increase work attendance among assembly personnel without impeding productivity.

\section{Research questions}

RQ1 How can SOC be used as a leadership approach in HFE practice?

RQ2 How was productivity influenced after implementing SOC-based managerial behaviour at three workplaces at Scania?

RQ3 How was quality influenced after implementing SOC-based managerial behaviour at three workplaces at Scania?

RQ4 How was work attendance influenced after this intervention?

RQ5 How was the number of rehabilitation cases influenced after this intervention?

\subsection{Lean}

Since the company studied in this project has systematised a lean approach, previous research and its relation to HFE are described in this section. Although lean has become one of the best-known process improvement methodologies, it is also fiercely debated (Samuel et al., 2015). The term lean was coined by John Krafcik to clarify the Toyota Production System's (TPS) less resource-intensive production compared with the mass production that was common in the Western world (Krafcik, 1988; Samuel et al., 2015). The concept became known to the world through the influential book The Machine that Changed the World (Womack et al., 1990), which found a dramatic difference in effectiveness between Japanese and Western car producers (Womack et al., 1990; Samuel et al., 2015). Over time, lean has evolved into a set of approaches; as a consequence there is no consensus about a clear definition (Hines et al., 2004; Pettersen, 2009; Samuel et al., 2015). Despite the lack of a clear definition of lean, many organisations around the world have started to implement it. However, many organisations have difficulty succeeding with their lean implementation efforts (Bhasin and Burcher, 2006; Emiliani, 2006; Liker and Ballé, 2013; Miina, 2012; Sohal and Eggleston, 1994; Spear and Bowen, 1999). One 
explanation for the difficulties is that they emphasise only the technical practices and misunderstand or neglect the critical role of human factors (Yang et al., 2012). Missing the role of humans in production is problematic, because the importance of people for productivity is clearly elucidated in the definition of productivity from the Asian Productivity Organization (APO). APO defines productivity as primarily about an attitude of the mind: people adding value to a work process, aided by machines and systems (APO, 2003). It is the mind-set that is fundamental in lean (Yamamoto and Bellgran, 2010); to succeed, managers must change their view of their role (Emiliani, 2006; Emiliani and Emiliani, 2013; Mann, 2010). Unfortunately, most organisations that aim for lean apparently lack an understanding of the importance of managers' behaviour (Emiliani, 2006; Emiliani and Emiliani, 2013; Liker and Ballé, 2013). The managers' role becomes to coach and develop people (Aij et al., 2015; Poksinska et al., 2013). Hasle et al. (2012) argue that it is important that studies on lean explore how lean practice can be developed so as to enhance positive job characteristics, such as meaning at work, transparency, participation, social support, job autonomy and skill utilisation.

\subsection{Health promotion and SOC theory}

Westgaard and Winkel (2011) argue that occupational health and ergonomics intervention research should focus on insights that balance worker well-being and production performance and thereby contribute to sustainable production systems. Larsson and Vinberg (2010) assert that leadership behaviour plays a critical role in the creation of successful, healthy, and effective organisations. In the field of health promotion, health is described as a resource for everyday life, with impact on individuals' social and personal resources as well as physical capabilities (WHO, 1998). According to Antonovsky (1996), health promotion practice should be based on a salutogenic perspective on health; that is, focusing on health-enhancing factors rather than the pathogenic perspective that focuses on disease-causing factors. It is interesting to explore if the outcome of an intervention focusing on health promotion might be less disease, resulting in less sick leave from work.

Antonovsky's salutogenic theory for health promotion is called SOC (Antonovsky, 1996). SOC theory consists of three basic elements: meaningfulness, the motivational component; comprehensibility, the cognitive component; and manageability, the behavioural component. Researchers have found the salutogenetic SOC theory to be relevant to the work context (Graeser, 2011; Vogt et al., 2013, 2016). Based on their literature review, Vogt et al. (2013) argue for a work-SOC concept; they believe that SOC theory in workplaces could reduce stress levels among personnel and also might have positive effects on work engagement. Graeser (2011) suggests that SOC in workplaces may decrease the risk of sick leave. Vogt et al. (2016; with reference to Kira, 2003) find that the increasing uncertainty and complexity in work life creates a need for sustainable development of employees, making their work more comprehensible, manageable and meaningful. Vogt et al. (2016) conclude in their study that a resourceful working environment can help build employees' SOC, leading to increased work engagement among employees. In a literature review that aimed to identify occupational, musculoskeletal and mental health effects of production system rationalisation, Westgaard and Winkel (2011) concluded that information, resonant management style, 
worker participation, support, group autonomy and procedural justice were factors with positive impact.

The managers of the rear axle and front axle assembly lines in the present study were inspired by HFE and its focus on both performance and less sick leave. A discussion started on how to practise HFE in their daily work. The managers decided to try to base their leadership on the health promotion theory SOC, with the goal to create and support feelings of meaningfulness, comprehensibility and manageability among employees at work. In other words, they wanted to explore if SOC was a possible practical tool in their daily HFE effort.

\subsection{Health, management and their relation to quality and productivity}

Health has been recognised as an important factor for quality of products and services and for productivity. Eklund (2000) argues that the only way to achieve quality for end customers is through quality in all work activities leading to delivery of the product or service. He states that a conditional requirement is that the work activities be free from risk of accidents and health impairments, and that the work conditions should promote wellness. Edwards and Jensen (2014) assert that the ergonomic profession aspires to ensure that design or redesign of production systems considers both productivity and employee well-being, and they state that there are many approaches to achieve this. Dul et al. (2012) also assert the importance of health, stating that performance influences well-being and vice versa. They further argue that performance and well-being are reduced if there is a gap between the environment and human capabilities and aspirations. Humans might perform below their standard and capability if parts of the work system act as obstacles instead of as support. Therefore, it is interesting to study whether this affects production, since the work environment is fitted to humans, and the result optimises both performance and well-being. Dul et al. (2012) point to the important role of managers in understanding the conditions for health, so they become able to create a healthy, supportive work environment.

\subsection{Change and resistance to it}

It is well known that change in organisations is a difficult task to succeed with and that change efforts in organisations often fail to reach their goals (Kotter, 2006; Kotter and Schlesinger, 2008); the situation is the same for ergonomic-based health interventions (Neumann et al., 2009). Managers generally know that bringing change to organisations often meets resistance, yet surprisingly, they rarely search systematically for sources of resistance before initiating change initiatives (Kotter and Schlesinger, 2008). Kotter and Schlesinger (2008) identify four common reasons for human resistance to change: a desire not to lose something of value, a misunderstanding of the change and its implications, a belief that the change does not make sense for the organisation and a low tolerance for change. Managers who are aware of these four common reasons gain a chance at predictability and to act (Kotter and Schlesinger, 2008).

At the outset when creating healthy workplaces, managers should have a holistic approach to health and be sure to include physical, psychological and social factors; it is also relevant to assess individual health as well as productivity (Kelloway and Day, 2005). Ergonomics aims to ensure that the design or redesign of a production system considers both employee well-being and productivity, and many approaches exist that do 
that (Edwards and Jensen, 2014). An important factor for success with interventions in organisations is the participation of different stakeholders (Neumann et al., 2009; Dul et al., 2012). Seppälä and Klemola (2004) argue that when people feel that their work is meaningful, are given autonomy, and are provided with opportunities to learn new things and to develop, they are involved and satisfied with their work. According to Kotter (1995), a change is fulfilled only when it has become a new behaviour that is rooted in shared values and social norms, a culture in the organisation that is naturally expressed as 'the way we do things'.

\section{Methodology}

\subsection{The case company - Scania}

The case company's history goes back to 1891, when Vabis began production of railroad cars in Södertälje, Sweden. Later, they started producing cars and trucks. In 1900, Scania was founded in Malmö, Sweden, to produce bicycles. To meet growing competition in Europe, Vabis and Scania merged in 1911. Today, Scania produces trucks, buses, and industrial and marine engines. Scania is established in 100 countries, with more than 49,000 people employed worldwide (Scania, 2017). The number of employees at Scania in Sweden in 2012 was 12,660 (Scania, 2012); the numbers increased to an average of 14,702 employees in 2016. Globally, work attendance experienced a slight decrease from 2012 to 2016 (to $95.9 \%$ ) but is described as remaining stable at around $96 \%$ (Scania, 2016).

\subsection{Scania Production System}

Scania was influenced by Toyota in the development of the SPS. SPS is described as a powerful instrument for productivity and as having played an important role in Scania's business success. SPS, whose purpose is to increase productivity and eliminate waste, is deeply anchored in the company culture. Giving personnel time to work with continuous improvement is seen as basic and part of the daily work; a consequence of this is that a big part of the work on improvements has shifted from engineers to the people working in production. Since Scania started to implement SPS, productivity has steadily increased. SPS is based on three basic values: customer first, respect for the individual, and elimination of waste.

SPS has four main principles:

- regular conditions and standardised work, which make it possible to detect deviations

- ' right from me', which means that no deviations from standard/quality are accepted to reach internal or external customers

- $\quad$ production according to need, which means that no production is performed unless a customer has signalled a need

- continuous improvements, meaning that regular conditions and standards should always be challenged and improved, and that deviations from the standard are handled so that they never occur again (Scania, 2018). 


\subsection{The three workplaces}

This study was done at three workplaces at Scania. The first two workplaces were the rear axle assembly line and front axle assembly line, which are two parts of Scania's axle and gearbox assembly unit, with the same management team. The third workplace was the engine assembly plant. The assembly work was performed during two shifts at all three workplaces. At the time of the study, the second author was working as production manager on the rear axle assembly line, and the third author was production manager on the front axle assembly line.

To our knowledge, this was the first time that SOC theory was used as a basis for leadership. Therefore, the managers of the two axle assembly lines saw these as 'pilot projects'. At the end of 2013, a new management team took over at Scania's axle and gearbox assembly unit, and the SOC-based leadership approach ended. However, on January 1, 2014, the 'pilot project' was repeated at Scania's engine assembly plant. See Table 1.

Table 1 Details of the interventions at the three Scania workplaces

\begin{tabular}{lcc}
\hline Workplace & Intervention started & Years data was collected \\
\hline Rear axle assembly & July 2012 & 2011-2013 (data for rehabilitation cases is \\
& & not available for 2011) \\
Front axle assembly & July 2012 & $2011-2013$ \\
Engine assembly & January 2014 & $2013-2017$ \\
\hline
\end{tabular}

Table 2 show the number of persons holding a position at the three workplaces who were participating in the intervention.

Table 2 Numbers of people participating in the intervention

\begin{tabular}{lccccc}
\hline Workplace & $\begin{array}{c}\text { Production } \\
\text { managers }\end{array}$ & Supervisors & $\begin{array}{c}\text { Workshop } \\
\text { managers }\end{array}$ & $\begin{array}{c}\text { Team } \\
\text { leaders }\end{array}$ & Operators \\
\hline Rear axle assembly & 1 & 5 & & 10 & 120 \\
Front axle assembly & 1 & 4 & 15 & 120 \\
Engine assembly plant & 1 & 13 & 4 & 40 & 350 \\
\hline
\end{tabular}

\subsection{The intervention process and data collection during implementation}

The intervention process comprised four areas: management education, including theories and tools; adoption to test a new management model; reflection within the group on the new approach; and, finally, broadening the implementation to new units in the organisation. Documenting the processes revealed what the managers said about the planning and implementation of the intervention, and how this intervention led to the changes. The process is presented in Table 3.

\subsection{Measures}

Measuring productivity can be complicated, since an array of methodologies is available (Del Gatto et al., 2011). According to Pritchard (1995, p.3), "productivity is how well a system uses its resources to achieve its goals." With that view on productivity, measures of quality, attendance and more are seen as leading to the fulfilment of goals (Pritchard, 1995). 
Table 3 The parallel process of implementation and data collection for research question 1

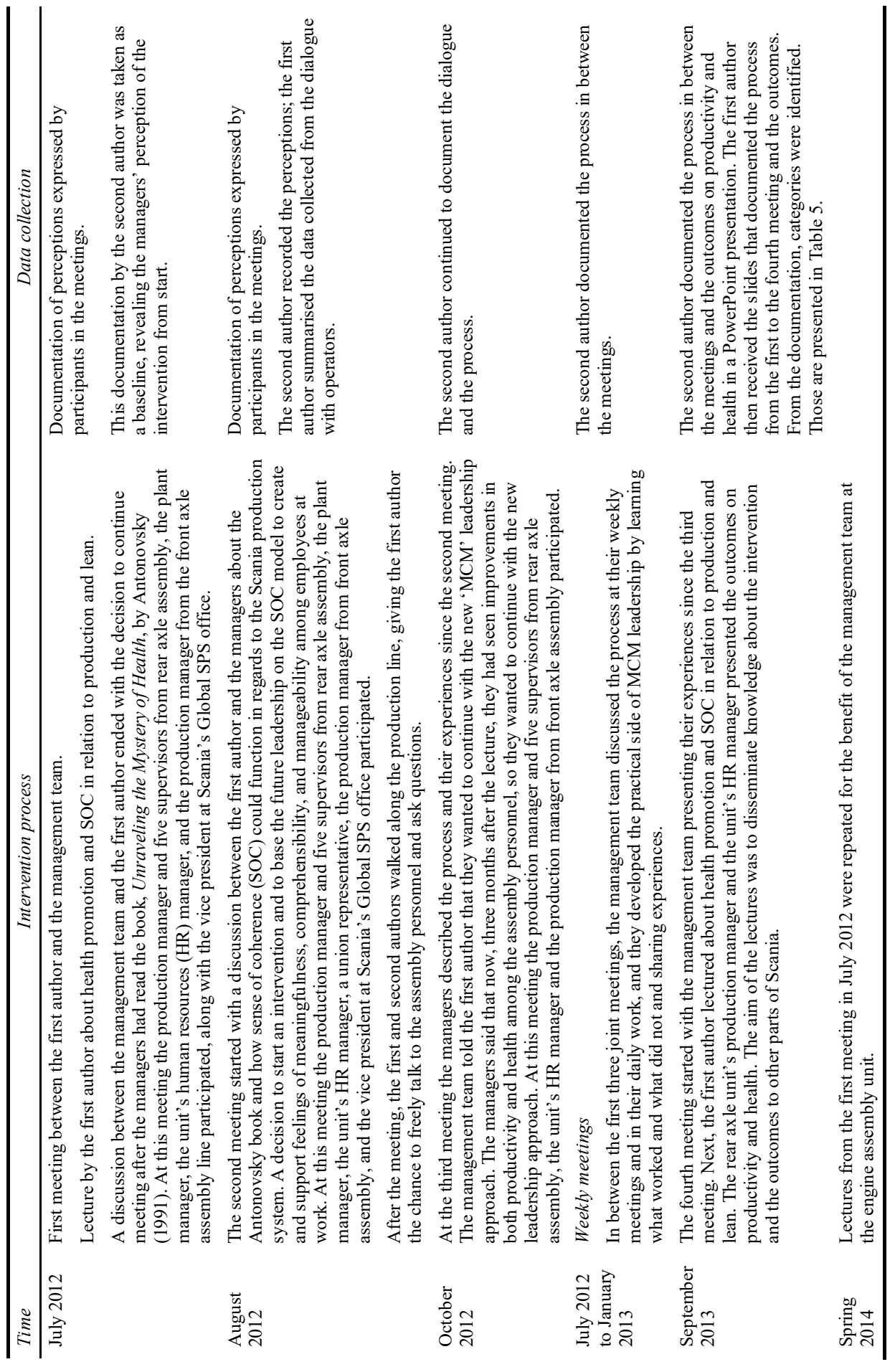


Health can be measured in different ways. According to Mattke et al. (2007), interest in measuring health effects on productivity has resulted in the development of numerous measurement instruments. In their review of such instruments, they conclude that established and validated instruments are lacking; they argue that improving and validating methods that measure health-related productivity loss is a task for future research (Mattke et al., 2007). According to Karasek and Theorell (1990), it is important to measure both productivity and health (or wellness) when an organisation's performance is measured.

The purpose of the pilot studies was to explore if SOC can be used as a leadership approach in HFE practice. That was done by following the implementation process through meetings with the managers to learn their experiences, as described in Table 3. The second author also documented the process in PowerPoint slides. After implementing SOC-based managerial behaviour at the three workplaces, Scania measured the outcomes through their system of follow-up key performance indicators (KPIs): productivity, quality, work attendance and numbers of rehabilitation cases. Table 4 shows the measures used to investigate the second, third, fourth and fifth research questions.

Table 4 Data collection follow-up after the intervention

\begin{tabular}{|c|c|c|c|}
\hline $\begin{array}{l}\text { Research } \\
\text { question }\end{array}$ & Measure & Key performance indicators & Analysis \\
\hline RQ2 & Productivity & $\begin{array}{l}\text { Number of components produced per } \\
\text { employee per year }\end{array}$ & $\begin{array}{l}\text { Increase or decrease in } \\
\text { number }\end{array}$ \\
\hline RQ3 & Quality & $\begin{array}{l}\text { Number of components per million } \\
\text { that fail to meet quality specifications }\end{array}$ & $\begin{array}{c}\text { Increase or decrease in } \\
\text { number }\end{array}$ \\
\hline RQ4 & $\begin{array}{l}\text { Work } \\
\text { attendance }\end{array}$ & Work attendance & Increase or decrease in $\%$ \\
\hline RQ5 & Rehabilitation & Number of rehabilitation cases & $\begin{array}{l}\text { Increase or decrease in } \\
\text { employees in } \\
\text { rehabilitation }\end{array}$ \\
\hline
\end{tabular}

\section{Results}

RQ1 was how SOC could be used as a leadership approach in HFE practice. Based on the managers' experiences and the dialogue described in the documentation of the process, the management team identified six changes in their managerial behaviour as important to enable them to practise the new leadership approach (which they called MCM, for meaningfulness, comprehensibility and manageability) and succeed in increasing both health and productivity. The six changes were:

1 obtain facts with your own eyes

2 practise present leadership

3 support the position owner

4 act fast on proposals and try them out 
5 react as quickly as possible to behaviour deviation

6 systematise and create a standard for rehabilitation cases.

See Table 5.

Table 5 Behaviour changes managers found important for the new leadership and success in increasing both health and productivity

\begin{tabular}{|c|c|}
\hline Categories & Summary based on qualitative analysis \\
\hline $\begin{array}{l}\text { Obtain facts } \\
\text { with your } \\
\text { own eyes }\end{array}$ & $\begin{array}{l}\text { Seen as crucial for basing decisions and managerial activities on facts obtained } \\
\text { from managers' own observations and/or questions from walks on the } \\
\text { production floor. These walks were seen as a way to grasp the real situation } \\
\text { instead of acting from their imaginations. }\end{array}$ \\
\hline $\begin{array}{l}\text { Practise } \\
\text { present } \\
\text { leadership }\end{array}$ & $\begin{array}{l}\text { Necessary to allow the managers to understand the current situation and obtain } \\
\text { the knowledge they needed to help the employees achieve SOC in their work. } \\
\text { The management team described their primary task as supporting the assembly } \\
\text { personnel, since they are the value creators from a customer perspective. }\end{array}$ \\
\hline $\begin{array}{l}\text { Support the } \\
\text { position } \\
\text { owner }\end{array}$ & $\begin{array}{l}\text { Even if many people are working at an assembly station through work rotation, } \\
\text { there is always one position owner at each assembly station, seen as the real } \\
\text { expert on the work done at his or her station. The manager's task was } \\
\text { described as not to provide solutions but to support the position owner to find } \\
\text { solutions to problems and with development work. Focussing on the position } \\
\text { owner was seen as a way to strengthen the level of meaningfulness, } \\
\text { comprehensibility and manageability among employees. }\end{array}$ \\
\hline $\begin{array}{l}\text { Act fast on } \\
\text { proposals and } \\
\text { try them out }\end{array}$ & $\begin{array}{l}\text { Any delay in acting on proposals was found to make assembly workers lose } \\
\text { interest in coming up with new proposals for improvements. The managers } \\
\text { said they would have to create a 'culture of courage' to try proposals fast and } \\
\text { not spend a lot of time on discussion. Because the assembly work was based on } \\
\text { standard operating procedures, they could always go back to them if a test } \\
\text { failed. The managers considered acting fast on improvement proposals to be } \\
\text { very important for meaningfulness, while trying out an idea was a good way to } \\
\text { develop employees' levels of comprehensibility and manageability regarding } \\
\text { development work- they could learn from the experience even if the trial was } \\
\text { not successful. }\end{array}$ \\
\hline $\begin{array}{l}\text { React as } \\
\text { quickly as } \\
\text { possible to } \\
\text { behaviour } \\
\text { deviation }\end{array}$ & $\begin{array}{l}\text { When managers determined the root cause of a behaviour deviation such as } \\
\text { late arrival to work or excessive sick leave, they preferred face-to-face } \\
\text { discussion to enhance comprehensibility about how the behaviour deviation } \\
\text { affected the team, thereby motivating better behaviour in the future. }\end{array}$ \\
\hline $\begin{array}{l}\text { Systematise } \\
\text { and create a } \\
\text { standard for } \\
\text { rehabilitation } \\
\text { cases }\end{array}$ & $\begin{array}{l}\text { A group of health professionals, together with managers and the individual, } \\
\text { create a plan for rehabilitation. The goal is to start the rehabilitation as quickly } \\
\text { as possible, thereby enhancing the individual's feeling of meaningfulness and } \\
\text { making it possible for him or her to get back to work or obtain a job elsewhere } \\
\text { in the company or outside the company. Supporting the individual with a } \\
\text { rehabilitation team of different professionals was seen as a way to also enhance } \\
\text { the individual's levels of comprehensibility and manageability. }\end{array}$ \\
\hline
\end{tabular}

These managerial behaviours can be understood as a practice-based leadership integrating SOC theory in HFE practice in a lean context.

Table 6 presents how the KPI's productivity, quality, work attendance and number of rehabilitation cases were influenced, addressing research questions 2-5. 
Table 6 Results of KPIs

\begin{tabular}{lccccccc}
\hline Rear axle assembly & 2011 & 2012 & 2013 & & & & \\
\hline Productivity/employee & 902 & 1,075 & 1,099 & & & \\
Quality (failures/million) & 2227 & 542 & 289 & & & \\
Attendance & $94 \%$ & $96 \%$ & $96.5 \%$ & & & \\
Rehabilitation cases & $\begin{array}{c}\text { Data not } \\
\text { available }\end{array}$ & 19 & 2 & & & & \\
& 2011 & 2012 & 2013 & & & & \\
\hline Front axle assembly & 1,000 & 1,081 & 1,252 & & & & \\
\hline Productivity/employee & 3,135 & 964 & 638 & & & & \\
Quality (failures/million) & $87 \%$ & $87 \%$ & $91 \%$ & & & & \\
Attendance & 28 & 21 & 11 & & & & \\
Rehabilitation cases & & & 2013 & 2014 & 2015 & 2016 & 2017 \\
\hline Engine assembly & & & 62.2 & 76.2 & 84 & 87.7 & 91.2 \\
\hline Productivity/employee & & & 10,140 & 5,801 & 3,020 & 2,466 & 2,138 \\
Quality (failures/million) & & & $107.2 \%$ & $93.3 \%$ & $92.3 \%$ & $93.3 \%$ & $95.6 \%$ \\
Attendance & & & 93 & 106 & 71 & 49 \\
Rehabilitation cases & & & & & & \\
\hline
\end{tabular}

Note: The first year shown for each workplace shows the status before the pilot project began.

\section{Discussion}

The goal for the managers was to decrease the rate of sick leave and rehabilitation cases and increase work attendance among assembly personnel without impeding productivity. The managers decided to base their leadership on the health promotion theory SOC in addition to the existing lean approach. In the intervention process, the management team identified six changes to their management practices as important to be able to practise SOC-based leadership and achieve their goal. These managerial principles, as described in the Results, can be understood as a practice-based management approach integrating SOC in lean. As a complement to Table 6, here are further details on the six management principles in relation to HFE, SOC and lean. The managers disclosed that 'obtaining facts with one's own eyes' and 'practising present leadership' are important principles enabling them to support people. Both of these principles were also an essential way for managers to find out if employees were experiencing meaningfulness, comprehensibility, and manageability in their daily work or not, according to the managers. For further research it is recommended that SOC data be structurally collected as a complement to data about work attendance and sick leave. Kotter and Schlesinger (2008) found that managers generally know that organisational changes often meet resistance from people, but they surprisingly rarely systematically search for sources of resistance before initiating change initiatives. Learning about the reasons for resistance to change gives managers a chance to predict and act on their predictions. During different phases in the intervention, managers spoke at meetings and those dialogues were documented (see Table 3 ). We conclude that practising present leadership and personally obtaining facts 
can be a useful approach for managers to use in their efforts to fit the environment to humans for positive outcomes in both performance and wellness, as also described by Dul et al. (2012).

Supporting the position owner means to develop his or her capacity to find solutions to problems and carry out development work, instead of the managers acting as solution providers. That is in line with the role of a lean manager as teacher and coach (Aij et al., 2015; Emiliani and Emiliani, 2013; Liker and Ballé, 2013; Liker and Hoseus, 2010; Poksinska et al., 2013). In the present study it also seems to be relevant in a lean-based company that wishes to implement an intervention based on SOC. One conclusion based on the documentation from this intervention is that employees' 'SOC' can be strengthened through the six enhancing principles and management. We found that there is support for that statement in our data but also in previous research. For example, Seppälä and Klemola (2004) found that people who feel their work to be meaningful and are given autonomy, opportunities to learn new things and a chance to develop themselves become involved and satisfied with their work.

The informants in this study also emphasised acting fast on proposals and trying them out; any delay in acting was described as leading to assembly personnel losing interest in development work. That is in line with Liker and Ballé (2013), who found that a key to handling suggestions successfully is to let the ownership of the idea remain with the employee who made the suggestion for improvement. Consequently, acting fast on proposals is important for people's feeling that it is meaningful to come up with ideas.

Likewise, managers should react as quickly as possible to behaviour deviations and seek their root causes. In this intervention, a standard was created for managers when they found behaviour deviations among personnel. Standards are an important issue in lean (Liker and Ballé, 2013).

At all three workplaces in the present study, the number of people undergoing rehabilitation decreased. That might be a result of systematising and creating a standard for rehabilitation cases, which the managers describe as a way to allow the individual to come back to work as soon as possible. Systematising and creating a standard for rehabilitation cases as described by the managers is worth further exploration.

The managers' role in lean is to coach and develop people (Aij et al., 2015; Poksinska et al., 2013). Dul et al. (2012) point to the important role of managers in understanding the conditions for health, allowing them to create a healthy, supportive work environment. The managers at the three workplaces read about health promotion and SOC theory and started to use SOC as a leadership approach.

At all three workplaces, productivity, quality and work attendance increased. The results are in line with the statement by Larsson and Vinberg (2010), who assert that leadership behaviour plays a critical role in the creation of successful, healthy and effective organisations. SOC theory is considered relevant to the work context (Graeser, 2011; Vogt et al., 2013, 2016). Furthermore, Graeser (2011) suggests that SOC in workplaces may decrease the risk of sick leave. The results from Scania confirm these statements. This study revealed that the SOC theory can be a basis for managers to support the creation of workplaces that decrease the rate of sick leave and rehabilitation cases and increase work attendance among assembly personnel without impeding productivity.

We further argue that our results indicate that SOC can be a tool for managers in practising HFE with the goal of creating workplaces with high performance and wellness. 
To combine lean and SOC theory as described can be seen as a contribution to Hasle et al.'s (2012) request to study how lean practice can be developed to enhance positive job characteristics.

This study indicates that concerns for performance start with concerns for the people creating the output.

\section{References}

Aij, K.H., Plette, M.D. and Joosten, G.M. (2015) 'A literature review of lean leadership attributes', Journal of Global Economics, Management and Business Research, Vol. 2, No. 4, pp.201-210.

Antonovsky, A. (1991) Hälsans mysterium [Unraveling the Mystery of Health], Natur \& Kultur, Stockholm.

Antonovsky, A. (1996) 'The salutogenic model as a theory to guide health promotion', Health Promotion International, Vol. 11, No. 1, pp.11-18.

Asian Productivity Organization (APO) (2003) Achieving Higher Productivity through Green Productivity [online] http://www.apo-tokyo.org/publications/ebooks/achieving-higherproductivity-through-gp-pdf-1-9mb/ (accessed 20 June 2019).

Bhasin, S. and Burcher, P. (2006) 'Lean viewed as a philosophy', Journal of Manufacturing Technology Management, Vol. 17, No. 1, pp.56-72.

Del Gatto, M., Di Liberto, A. and Petraglia, C. (2011) 'Measuring productivity', Journal of Economic Surveys, Vol. 25, No. 5, pp.952-1008.

Dul, J., Bruder, R., Buckle, P., Carayon, P., Falzon, P., Marras, W.S., Wilson, J.R. and van der Doelen, B. (2012) 'A strategy for human factors/ergonomics: developing the discipline and profession', Ergonomics, Vol. 55, No. 4, pp.377-395.

Edwards, K. and Jensen, P.L. (2014) 'Design of systems for productivity and well being', Applied Ergonomics, Vol. 45, No. 1, pp.26-32.

Eklund, J. (2000) 'Towards a framework for quality of interactions between humans, technology and organization', Proceedings of the Human Factors and Ergonomics Society Annual Meeting, Vol. 44, No. 12, pp.2-463-2-466.

Emiliani, M.L. (2006) 'Origins of lean management in America: the role of Connecticut businesses', Journal of Management History, Vol. 12, No. 2, pp.167-184.

Emiliani, M.L. and Emiliani, M. (2013) 'Music as a framework to better understand lean leadership', Leadership \& Organization Development Journal, Vol. 34, No. 5, pp.407-426.

Graeser, S. (2011) 'Salutogenic factors for mental health promotion in work settings and organizations', International Review of Psychiatry, Vol. 23, No. 6, pp.508-515.

Hasle, P., Bojesen, A., Jensen, P.L. and Bramming, P. (2012) 'Lean and the working environment: a review of the literature', International Journal of Operations \& Production Management, Vol. 32, No. 7, pp.829-849.

Hines, P., Holweg, M. and Rich, N. (2004) 'Learning to evolve: a review of contemporary lean thinking', International Journal of Operations \& Production Management, Vol. 24, No. 10, pp.994-1011.

Karasek, R. and Theorell, T. (1990) Healthy Work-Stress, Productivity, and the Reconstruction of Working Life, Basic Books, New York.

Kelloway, K.E. and Day, A. (2005) 'Building healthy workplaces: where we need to be', Canadian Journal of Behavioural Science, Vol. 37, No. 4, pp.309-312.

Kira, M. (2003) From Good Work to Sustainable Development: Human Resources Consumption and Regeneration in the Post-Bureaucratic Working Life, unpublished $\mathrm{PhD}$ thesis, Royal Institute of Technology, Stockholm, Sweden. 
Kotter, J.P. (1995) 'Leading change - why transformation efforts fail', Harvard Business Review, March-April, Vol. 73, No. 2, pp.59-67.

Kotter, J.P. (2006) Leading Change, Harvard Business Press, Boston.

Kotter, J.P. and Schlesinger, L.A. (2008) 'Choosing strategies for change', Harvard Business Review, July-August, Vol. 86, Nos. 7/8, pp.130-139.

Krafcik, J. (1988) 'Triumph of the lean production system', Sloan Management Review, Fall, Vol. 30, No. 1, pp.41-52.

Larsson, J. and Vinberg, S. (2010) 'Leadership behaviour in successful organisations: universal or situation-dependent?', Total Quality Management, Vol. 21, No. 3, pp.317-334.

Liker, J. and Ballé, M. (2013) 'Lean managers must be teachers', Journal of Enterprise Transformation, Vol. 3, No. 1, pp.16-32.

Liker, J.K. and Hoseus, M. (2010) 'Human resources development in Toyota culture', International Journal of Human Resources Development and Management, Vol. 10, No. 1, pp.34-50.

Mann, D. (2010) Creating a Lean Culture: Tools to Sustain Lean Conversions, CRC Press, Taylor \& Francis Group, Oxford, UK.

Mattke, S., Balakrishnan, A., Bergamo, G. and Newberry, S.J. (2007) 'A review of methods to measure health-related productivity loss', The American Journal of Managed Care, Vol. 13, No. 4, pp.211-218.

Miina, A. (2012) 'Lean problem: why companies fail with lean implementation', Management, Vol. 2, No. 5, pp.232-250.

Neumann, P.W., Ekman, M. and Winkel, J. (2009) 'Integrating ergonomics into production system development - the Volvo Powertrain case', Applied Ergonomics, Vol. 40, No. 3, pp.527-537.

Pettersen, J. (2009) 'Defining lean production: some conceptual and practical issues', The TQM Journal, Vol. 21, No. 2, pp.127-142.

Poksinska, B., Swartling, D. and Drotz, E. (2013) 'The daily work of lean leaders - lessons from manufacturing and healthcare', Total Quality Management \& Business Excellence, Vol. 24, Nos. 7-8, pp.886-898.

Pritchard, R.D. (1995) Productivity Measurement and Improvement - Organizational Case Studies, Praeger/Greenwood, Westport, CT.

Robinson, A.G. and Schroeder, D.M. (2009) 'The role of front-line ideas in lean performance improvement', Quality Management Journal, Vol. 16, No. 4, pp.27-40.

Rodríguez, D., Buyens, D., Van Landeghem, H. and Lasio, V. (2015) 'Impact of lean production on perceived job autonomy and job satisfaction: an experimental study', Human Factors and Ergonomics in Manufacturing \& Service Industries, Vol. 26, No. 2, pp.159-176.

Samuel, D., Found, P. and Williams, S.J. (2015) 'How did the publication of the book The Machine that Changed the World change management thinking? Exploring 25 years of lean literature', International Journal of Operations \& Production Management, Vol. 35, No. 10, pp.1386-1407.

Scania (2012) Annual Report 2012 [online] https://www.scania.com/group/en/wp-content/uploads/ sites/2/2015/09/Scania-Annual-report-2012-ENG-tcm40-362754.pdf (accessed 20 June 2019).

Scania (2016) Annual and Sustainability Report 2016 [online] https://www.scania.com/group/en/ wp-content/uploads/sites/2/2017/03/scania-annual-and-sustainability-report-2016.pdf (accessed 20 June 2019).

Scania (2017) Om Scania [online] https://www.scania.com/se/sv/home/experience-scania/aboutus.html (accessed 20 June 2019).

Scania (2018) The Scania Way - The Way We Work [online] https://www.scania.com/group/en/thescania-way/ (accessed 20 June 2019).

Seppälä, P. and Klemola, S. (2004) 'How do employees perceive their organization and job when companies adopt principles of lean production?', Human Factors and Ergonomics in Manufacturing, Vol. 14, No. 2, pp.157-180. 
Sohal, A.S. and Eggleston, A. (1994) 'Lean production: experience among Australian organizations', International Journal of Operations \& Production Management, Vol. 14, No. 11, pp.35-51.

Spear, S. and Bowen, K.H. (1999) 'Decoding the DNA of the Toyota Production System', Harvard Business Review, September-October, Vol. 99, No. 6, pp.97-106.

Tappura, S., Syvänen, S. and Saarela, K.L. (2014) 'Challenges and needs for support in managing occupational health and safety from managers' viewpoints', Nordic Journal of Working Life Studies, Vol. 4, No. 3, pp.31-51.

Vogt, K., Hakanen, J.J., Jenny, G.J. and Bauer, G.F. (2016) 'Sense of coherence and the motivational process of the job-demands-resources model', Journal of Occupational Health Psychology, Vol. 21, No. 2, pp.194-207.

Vogt, K., Jenny, G.J. and Bauer, G.F. (2013) 'Comprehensibility, manageability and meaningfulness at work: construct validity of a scale measuring work-related sense of coherence', SA Journal of Industrial Psychology, Vol. 9, No. 1, pp.1-8.

Westgaard, R.H. and Winkel, J. (2011) 'Occupational musculoskeletal and mental health: significance of rationalization and opportunities to create sustainable production systems - a systematic review', Applied Ergonomics, Vol. 42, No. 2, pp.261-296.

Womack, J.P., Jones, D.T. and Roos, D. (1990) The Machine that Changed the World, Rawcon Associates, New York.

World Health Organization (WHO) (1998) Health Promotion Glossary [online] http://www.who. int/healthpromotion/about/HPR\%20Glossary\%201998.pdf?ua=1 (accessed 20 June 2019).

Yamamoto, Y. and Bellgran, M. (2010) 'Fundamental mindset that drives improvements towards lean production', Assembly Automation, Vol. 30, No. 2, pp.124-130.

Yang, C.C., Yeh, T.M. and Yang, K.I. (2012) 'The implementation of technical practices and human factors of the Toyota Production System in different industries', Human Factors and Ergonomics in Manufacturing \& Service Industries, Vol. 22, No. 6, pp.541-555. 